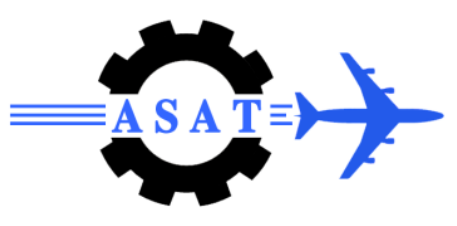

\title{
Ground Response due to Buried Structure Construction Process
}

\author{
S.N. Mhana ${ }^{*}$, S.A. Mazek ${ }^{\dagger}$, N.M. Nagy ${ }^{\ddagger}$
}

\begin{abstract}
Deep aircraft shelter and deep fortification are major projects of buried structures in military purposes. The Greater Cairo metro and El-Azhar road tunnels have been constructed as major projects of buried structures in Cairo City. Deep fortification construction causes movements in surrounding soil. Ground movement is an important factor during buried structure construction. Buried structure construction in cohesionless soil is a sophisticated process leading to cause potential damage to exist surface and subsurface fortification structures. Ground movements depend on soil properties, buried structure depth, buried structure diameters, and method of construction.
\end{abstract}

In this study, the finite element analysis (FEA) is used to predict surface displacement due to buried structure process based on case study. Surface displacement equation (SDE) proposed by Peck and Schmidt (1969) is also used to calculate surface displacement due to buried structure construction process. For assessing the reliability of the FEA, a case history along the Greater Cairo Metro tunnel Line 2 is considered. A comparison between the field measurements and those obtained by the FEA and the SDE is made. The surface ground movements obtained by the SDE are examined with those obtained by the FEA at different sand soil densities. However, the SDE does not consider impact of different sand soil types.

The surface settlement profile computed by the SDE is in poor agreement with those obtained by the FEA in loose to medium sandy soil. The surface settlement profiles computed by the SDE agree well with those calculated by the FEA in dense and very dense sandy soil. Finally, the finite element analysis is a good tool to analyze different sandy soil densities at which different sand soil stress and strength parameters are considered in the FEA.

Keywords: Tunneling, settlement, numerical modeling and analysis, displacement, design, deformations.

\section{Introduction}

Tunneling is increasingly being used to provide infrastructure such as transportation and utilities in densely populated urban areas (Compo and Richards, 1998; El-Nahhass et al., 1994). Tunnels are often cost-effective as an alternative solution to over-ground structure. However, the over-ground structure causes risk and problem during construction processes (Abdel-Salam, 1998; El-Nahhass, 1999). The number of tunnels in big cities under construction is increasing worldwide. Cairo Metro Line 2 includes $6 \mathrm{~km}$ of surface construction and $13 \mathrm{~km}$ of underground construction (Abdel-Salam, 1998).

\footnotetext{
Syrian Air Forces, Syria, Samermhanna@yahoo.com .

Egyptian Armed Forces, Egypt, samazek@yahoo.com .

${ }^{\ddagger}$ Egyptian Armed Forces, Egypt, nabilmnagy@yahoo.com . 
Tunnel construction causes movements in surrounding soil. Ground movement is an important factor during design phase and selection of appropriate method of tunnel construction. Tunneling in cohesionless soil is a sophisticated process leading to move soil and subsurface structures. The state of stress and the soil displacement around a tunnel system are affected by construction process of tunnel (Ahmed, 1994; El-Nahhass, 1986; Mazek and El-Tehawy, 2008). The influence zone due to tunneling depends on many parameters such as type of subsoil properties, tunnel depth, tunnel geometry, and tunneling method. Many investigators employed finite element analysis to predict ground deformation and stress change during tunneling (Ahmed, 1994; El-Nahhass, 1999; Mazek and El-Tehawy, 2008). The tunnel excavation can be modeled by finite element method under different soil conditions, different tunnel geometries, and different construction procedures (Ahmed, 1994; El-Nahhass, 1986; El-Nahhass, 1999; Mazek et al., 2001a; Mazek et al., 2001b; Mazek and ElTehawy, 2008; Ezzeldine, 1999).

In this paper, a 2-D finite element model (FEM) is proposed to predict surface displacement due to tunneling. The modeling of such a problem should include details of tunnel construction phases and associated changes of stresses around the tunnels. A nonlinear stressstrain constitutive model is adopted for soil media surrounding the tunnel. A case study on the Greater Cairo Metro tunnel Line 2 (Fig. 1) is conducted to assess the accuracy of the finite element analysis (FEA). The computed surface settlements are compared with the field measurements. A good agreement is found. The main objective of this paper is to examine surface displacement obtained by both the FEA and the surface displacement equation (SDE) developed by Peck and Schmidt (1969). The 2-D finite element analysis considers parameters of different sand soil densities. However, the SDE does not consider influence of different sand soil types on surface settlement due to tunneling.

The subsurface soil profile along the Greater Cairo Metro is shown in Fig. 1 (EL-Nahhass, 1999; NAT, 1993, 1999, 2008). The Geotechnical properties of soil in central Cairo city are presented in Table 1 (EL-Nahhass, 1999; NAT, 1993, 1999, 2008).

\section{Finite Element Model}

The finite element code Plaxis-V8.2 is used to model tunnel system performance. Analyses of displacement and stress around tunnel system are carried out using a 2-D plane strain finite element taking into account behavior of tunnel lining and soil media. The soil, the tunnel lining, and the interface medium are simulated using appropriate finite elements model as shown in Fig. 2. Numerical modeling of tunnel system reflects the ground continuum and the tunnel lining. In addition, the compatibility and equilibrium condition at the interface between the soil and the tunnel system are idealized in the numerical model. Six nodes triangular 2-D plane strain element is used to model soil media. 2-D beam element is used to model the tunnel lining.

The finite element analysis is used to determine displacement and stresses caused by acting loads. These loads depend mainly on overburden depth above the tunnel under effect of initial in-situ stresses. The initial stresses include vertical stresses and horizontal stresses. A nonlinear stress-strain constitutive model is adopted for soil around tunnel system. A yield function of the Mohr-Coulomb and a plastic potential function of the Drucker-Prager are employed. Linear elastic behavior is assumed for the tunnel liner. The interface between the soil medium and the tunnel lining is simulated using appropriate finite elements. 
Boundary conditions are defined to provide stability of tunnel system. The vertical boundaries of the 2-D finite elements model are restrained by roller supports to prevent a movement normal to the boundaries. The horizontal plane at the bottom of the mesh represents a rigid bedrock layer and the movement at this plane is restrained in two directions. The movement at upper horizontal plane is free to simulate a free ground surface. A convergence study is conducted based on mesh refinement, model dimensions, and appropriate selection of element types. The optimum meshes are studied and shown in Fig. 2.

\section{Properties of Model Materials}

The geological formations along Greater Cairo Metro line 2 projects are typical Cairo Nile Alluvial deposits (NAT, 1993, 1999). The tunnels were mostly bored in slightly sand. The ground water table varies between $2 \mathrm{~m}$ and $4 \mathrm{~m}$ from ground surface (NAT, 1993, 1999). Four distinct soil layers were encountered. A fill layer extends three meters from ground surface. The fill layer consisted of asphalt, broken red bricks, and stones. A natural deposit of stiff overconsolidated silty clay layer under the fill layer is varied from $4 \mathrm{~m}$ to $10 \mathrm{~m}$. This deposit includes occasional sand and silt partings. Beneath the silty clay layers, the silty sandy layer extends from $0.25 \mathrm{~m}$ to $1.0 \mathrm{~m}$. Beneath the silty sand layers, the sandy layer extends down to the bedrock.

Soil parameters were derived from in-situ and laboratory tests. The main Geotechnical parameters used in the 2-D FEA are presented in Table 1. The circular tunnel lining consists of seven segments and one key. The length of the ring is $1.5 \mathrm{~m}$ long. The thickness of tunnel lining is $400 \mathrm{~mm}$. The characteristics of the tunnel lining are tabulated in Table 2 (NAT, 1993, 1999, 2008).

\section{Tunnel Performance under Various Parameters}

The SDE proposed by Peck and Schmidt (1969) does not consider impact of different sand densities. However, the FEA takes into account strength and stress parameters of different sand soil types. In this study, the FEA is based on different types of cohesionless soils. The stress and the strength parameters of loose, medium, dense, and very dense sand are considered in the FEA (Duncan et al., 1980). The soil parameters required to model performance of tunnel system are presented in Table 3 (Duncan et al., 1980).

Diameter of tunnel is varied from $5 \mathrm{~m}, 7.5 \mathrm{~m}, 10 \mathrm{~m}$, and $12.5 \mathrm{~m}$. The tunnel is located at different types of cohesionless soils (loose sand, medium sand, dense sand, and very dense sand). The numerical analysis is carried out using the drained soil modulus $\left(\mathrm{E}_{\mathrm{s}}\right)$ calculated by the Janbu equation (1963) using different soil parameters as tabulated in Table 3 as the tunnel passes through sand layer. The variation of soil modulus $\left(\mathrm{E}_{\mathrm{s}}\right)$ with confining pressure is related to effective pressure based on Janbu's empirical equation (Janbu, 1963) as presented in Eq. (1). The different soil parameters $(m, n)$ are selected to simulate the behavior of different soil types (Duncan et al., 1980).

$$
E_{s}=m P_{a}\left(\frac{\sigma_{3}}{P_{a}}\right)^{n}
$$

where; the modulus number $(\mathrm{m})$ and the exponent number $(\mathrm{n})$ are both pure numbers, $\mathrm{P}_{\mathrm{a}}$ is the atmospheric pressure expressed in appropriate units, and $\sigma_{3}$ is effective confining pressure. 
The surface displacements (surface settlement) are estimated using empirical equation developed by Peck and Schmidt (1969) as presented in Eq. (2). The surface displacement trough is calculated by the normal Gaussian probability curve as shown in Fig. 3.

$$
\mathrm{S}=\mathrm{S}_{\max } \exp \left(\frac{-x^{2}}{2 i^{2}}\right)
$$

where; $\mathrm{S}$ is surface displacement, $\mathrm{S}_{\max }$ is maximum surface settlement at the point above tunnel centerline, $\mathrm{x}$ is distance from tunnel centerline in transverse direction, and $i$ is horizontal distance from tunnel centerline to point of inflection of settlement trough.

Based on the case study involving medium sand, $S_{\max }$ is recorded in the field. For loose sand, dense sand, and very dense sand, $S_{\max }$ is estimated using the 2-D finite element analysis. Attwell el at. (1986) proposed (i) parameter included in the SDE as presented in Eq. 3.

$$
\frac{i}{R}=\alpha\left(\frac{Z}{2 R}\right)^{n} \quad, \quad \alpha=1, \mathrm{n}=1
$$

where; $\mathrm{Z}$ is overburden depth from ground surface to C.L of tunnel, $\mathrm{R}$ is radius of tunnel, and $\alpha$ and $\mathrm{n}$ are constant parameters.

\section{Soil-Tunnel Behavior}

This case studied here is located along the Greater Cairo Metro Line 2, as shown in Fig. 1. The 2-D finite element model is used to predict the performance of the metro tunnel by computing the surface settlement. The overburden depth from ground surface to crown of the metro tunnel is $18 \mathrm{~m}$. The computed values are compared with the field measurements so as to understand the behavior of the metro tunnel system. This comparison is used to assess the accuracy of the numerical model, as shown in Fig. 4. The comparison shows that there is a good agreement between the computed and measured results.

The stress changes in soil around the metro tunnel system due to tunneling are also investigated to study detailed tunnel system behavior. For the metro tunnel, the soil stress analysis has been undergone four steps of change. These steps correspond to the construction of the metro tunnel. The loading steps are simulated using the 2-D FEA. First, the initial principal stresses are computed with the absence of the metro tunnel. Second, the excavation of the tunnel is modeled by means of the finite element method. The metro tunnel excavation is simulated by the removal of those elements inside the boundary of the tunnel surface to be exposed by the excavation. Third, the movements and stress changes induced in the soil media are calculated. Fourth, the calculated changes in stresses are then added to the initial stresses computed from the first step to determine the combined stresses resulting from the metro tunnel construction. The calculated vertical effective stress around the metro tunnel is also illustrated in Fig. 5.

Based on the good agreement between the computed and measured values, one can proceed to use the 2-D numerical model to explore other aspects of the tunnel system performance under the tunnel construction. In fact, the proposed model can help to predict the ground surface displacement at the different sandy soils. 


\section{Surface Displacement due to Tunnelling}

The surface displacement profile above a tunnel with diameter 9.48 meters are calculated and plotted in Fig. 6 to Fig. 9 using the SDE. The FEA is also conducted to determine the surface displacements due to tunneling in different sandy soils (loose sand, medium sand, dense sand, and very dense sand) based on different ground losses $\left(\mathrm{V}_{L}\right)$. The average values of the different sandy soil parameters adopted in the finite element analysis are summarized in Table 3 (Duncan et al., 1980). The volume loss is considered in this study. The volume loss is the ratio of the difference between the excavated soil volume and the tunnel volume over the excavate soil volume. The volume loss ranged from $1.5 \%$ to $4.5 \%$ and reached $6 \%$ at some locations (El-Nahhass, 1999). The volume loss of $4 \%$ is adopted in this study.

The numerical analysis is carried out using the unload-reload modulus $\left(E_{u r n}\right)$ for the soil based on Janbu's equation [Eq. 1] with different nonlinear soil parameters. The analysis is performed through the following main stages. The loading of the metro tunnel construction using the FEA includes: (1) initial soil condition before the construction of the metro tunnel; (2) removal of the soil inside the boundary of the metro tunnel surface; and (3) construction of the metro tunnel liners. Based on the FEA, the surface displacements along the centerline of the metro tunnel for different sandy soil types are presented in Fig. 6 to Fig. 9. However, the results obtained by the surface displacement equation (SDE) are examined with those obtained by the finite element analysis (FEA).

In the case of loose sand, the surface displacement profiles obtained by both the FEA and the SDE are shown in Fig. 6. The comparison shows that the surface displacements obtained by the finite element analysis are higher than those calculated by the surface displacement equation. However beyond $20 \mathrm{~m}$ from the centerline of the tunnel, the surface displacement calculated by the FEA has different shape than this calculated by the SDE. The result reveals that the surface settlement profile obtained by the SDE does not agree well with those obtained the FEA.

In the case of medium sand, the surface displacement profiles obtained by both the FEA and the SDE are shown in Fig. 7. The comparison shows that the surface displacements obtained by the FEA are higher than those calculated by the SDE. However beyond $20 \mathrm{~m}$ from the centerline of the tunnel, the surface displacement calculated by the FEA has different shape than this calculated by the SDE. The result reveals that the surface settlement profile obtained by the SDE does not agree well with those obtained the FEA.

Figure 8 shows the comparison between the results obtained by the FEA with those obtained by the SDE for dense sand. The comparison indicates that the surface displacement profile computed by the FEA has the same trend as the surface displacement profile calculated by the SDE. It is also observed that the surface displacements calculated by the FEA are larger than those calculated by surface displacement equation in the region beyond $20 \mathrm{~m}$ from the centerline of the tunnel. In the region between the centerline of the tunnel and $20 \mathrm{~m}$ from centerline of the tunnel, the surface displacements calculated by the FEA is the same as those calculated by the SDE. Generally, the results obtained by the finite element analysis agree well with those obtained by the surface displacement equation.

Figure 9 also shows the comparison between the results obtained by the FEA with those obtained by the SDE for dense sand. The comparison again shows that the surface displacement profile computed by the FEA has the same trend as the surface displacement profile calculated by the SDE. It is also observed that the surface displacements calculated by 
the FEA are larger than those calculated by surface displacement equation in the region beyond $20 \mathrm{~m}$ from the centerline of the tunnel. In the region between the centerline of the tunnel and $20 \mathrm{~m}$ from centerline of the tunnel, the surface displacements calculated by the FEA is the same as those calculated by the SDE. The results obtained by the finite element analysis agree well with those obtained by the surface displacement equation.

Therefore, the finite element analysis gives a better estimation of surface settlement as demonstrated with the comparison between the calculated and the measured settlements in medium dense soils involved in the case study. For the loose and medium sandy soils, ignoring the appropriate soil characteristics in the surface displacement equation (Eq. 2) probably leads to larger error and further deviation from the actual values. The surface displacement readings obtained by the FEA is more conservative than those calculated by the SDE.

The difference between the two sets of computed settlements is noticed in loose sand and in medium sand. The difference between the two sets of computed settlements lies in the use of the width parameter (i) as presented in Eq. (3). This equation is used for cohesionless soils but does not take into account the different geotechnical parameters associated with different densities of cohesionless soil. The proposed finite elements model takes into account the effects of the characteristics of the cohesionless soils of different densities. Therefore, the differences between surface displacement profiles obtained by the FEA with those obtained by the SDE may be due to the value of the shear strength and stress parameters for the soil media around tunnel system adopted in the 2-D nonlinear FEA.

\section{Conclusions}

Based on the proposed 2-D finite element model, the following conclusions are presented due to tunneling through different sand soil types.

- The 2-D nonlinear numerical model is applicable to analyze and predict detailed performance of tunnel systems.

- The results calculated by the proposed 2-D nonlinear finite element model have a good agreement with the field data.

- The predicated surface settlements due to tunneling underestimate by up to $10 \%$ from the field measurements. The discrepancy between the calculated and the field readings may be due to the stress-strain soil parameters and the strength soil parameters.

- Surface settlement profile computed by the surface displacement equation (SDE) by Peck and Schmidt (1969) is in reasonable agreement with surface settlement profile computed by the 2-D finite element analysis in dense to very dense sand soil.

- Surface settlement profile calculated by the SDE does not agree well with surface settlement profile calculated the 2-D FEA in loose and medium sand soil.

- The surface displacement equation proposed by Peck and Schmidt (1969) does not consider the impact of different sandy densities soil types. However, the finite element analysis takes into account strength and stress parameters of different sand densities.

- The surface settlement profiles calculated by the finite element analysis are more conservative than those computed by the surface displacement equation at different sand densities. 


\section{References}

[1] Ahmed, A.A. (1994). Analysis of deck road tunnels. Proceedings of the international congress on tunneling and ground condition, Abdel Salam (ed.), Cairo, Egypt. Published by Balkema, Rotterdam.

[2] Abdel-Salam, M.E. (1998). Urban constraints on underground works the Cairo metrocase histories. Egyptian society presentation, Cairo.

[3] Attwell, P.B., Yeates, J., and Selby, A.R. 1986. Soil Movement induced by tunneling and their effects on Pipelines and structures. Blackie and son Ltd. Published in the USA by Chapman and Hall.

[4] Byrne, P.M., Cheung, H., and Yan, L. (1987). Soil parameters for deformation analysis of sand masses. Canadian Geotechnical Journal. 24, 366-376.

[5] Compo, D.W., and Richards, D.P. (1998). Geotechnical challenges faced on line 2 of the Greater Cairo Metro System. ASCE, Big dig around the world. USA.

[6] Duncan, J.M., and Chang, C.Y. (1970). Nonlinear Analysis of Stress and Strain in Soils. Journal of the Soil Mechanics and Foundation Div. ASCE, Vol. 96, No. SM5. September.

[7] Duncan, J.M., Byrne, P.M., Wong, K.S., and Mabry, P. (1980). Strength, stress-strain and bulk modulus parameters for finite element analysis of stresses and movements in soil masses. University of California, Berkeley, CA. Report no. UCB/GT/80-01.

[8] Janbu, N. 1963. Soil compressibility as determined by oedometer and triaxial tests. European conference on soil mechanics of foundation engineering. Wiesbaden. Germany. Vol. 1, pp. 19-25.

[9] El-Nahhas, F. 1986. Spatial mode of ground subsidence above advancing shielded tunnels. Proc. Of International. Congress on Large underground Opening, Fireze, Italy, Vol. 1, pp. 720-725.

[10] El-Nahhass, F.M., Ahmed, A.A., El-Gammal, M.A., and Abdel Rahman, A.H. (1994). Modeling Braced Excavation for Subway station. Proceedings of the international congress on tunneling and ground condition, Abdel Salam (ed.), Cairo, Egypt. Published by Balkema.

[11] El-Nahhass, F. M. 1999. Soft ground tunneling in Egypt. Geotechnical challenges and Expectations. Proc. of the Tunneling and Underground Space Technology, Vol. 14, No. 3 , pp. $245-256$.

[12] Ezzeldine, O.Y. (1999). Estimation of the Surface Displacement Field Due to Construction of Cairo Metro Line El-Khalafawy- St.Thereses. Tunneling and underground space technology, Vol. 14, No. 3, pp. 267-279. Published by Elsevier science Ltd.

[13] Mazek, S.A., Law, K.T., and Lau, D.T. (2001a). Effect of grouting on soil reinforcing and tunnel deformation. International Underground Infrastructure Research Conference, Waterloo University, Kitchener, Canada.

[14] Mazek, S.A., Law, K.T., and Lau, D.T. (2001b). 3-D Analysis on the Performance of a Grouted Tunnel. Canadian Geotechnical Conference. Calgary. Canada. Vol. 1, pp. 111-119.

[15] Mazek, S.A, and El-Tehawy, E.M. 2008. Impact of Tunneling Running Side-by-Side to An Existing Tunnel on Tunnel Performance using Non-linear Analysis. Proc of the $7^{\text {th }}$ ICCAE. 27-29 May, 2008. Cairo, Egypt.

[16] National Authority for Tunnels (NAT), 1993, Project Document.

[17] National Authority for Tunnels (NAT), 1999, Project Document.

[18] National Authority for Tunnels (NAT), 2007, Project Document.

[19] O'Reilly, M. P. and New, B. M. 1982. Settlement above tunnels in the United Kingdom their magnitude and production. Tunneling conference. London. pp. 173- 181. 
[20] Peck, R. B. and Schmidt, B. 1969. Deep excavations and tunneling in soft ground. Proc. Of the $17^{\text {th }}$ International Conf. On Soil Mechanics and Foundation Engineering, Mexico City, Mexico, pp. 225-240.

Table 1: Geotechnical properties in Central Cairo City

\begin{tabular}{l|c|c|c|c}
\hline \multicolumn{1}{c|}{ Layer } & Fill & Silty-clay & Silty sand & Sand \\
\hline \hline Bulk density $\gamma_{\mathrm{b}}\left(\mathrm{t} / \mathrm{m}^{3}\right)$ & 1.8 & 1.9 & 1.85 & 2.0 \\
\hline Drained Poisson's Ratio $\mathrm{V}_{\mathrm{s}}$ & 0.4 & 0.35 & 0.35 & 0.30 \\
\hline Effective Angle of initial Friction $(\varphi)^{\circ}$ & 20 & 26 & 30 & 37 \\
\hline Effective Cohesion C $\left(\mathrm{KP}_{\mathrm{a}}\right)$ & 0 & 10 & 0 & - \\
\hline Standard penetration $($ blows/0.3m) & $4-20$ & $13-15$ & - & 35 \\
\hline Modulus Number $(\mathrm{m})$ & 300 & 325 & 400 & $400-700$ \\
\hline Exponent Number $(\mathrm{n})$ & 0.74 & 0.6 & 0.6 & $0.5-0.6$ \\
\hline Drained Modulus of Elasticity $\mathrm{E}_{\mathrm{s}}\left(\mathrm{t} / \mathrm{m}^{2}\right)$ & 1000 & 1200 & 3000 & 7000 \\
\hline Over Consolidation Ratio $(\mathrm{OCR})$ & 1 & 1.5 & - & - \\
\hline Coefficient of Lateral Earth Pressure $\mathrm{K}_{0}$ & 1 & 0.8 & 0.5 & 0.39 \\
\hline \hline
\end{tabular}

Table 2: Characteristics of the tunnel lining

\begin{tabular}{c|c|c|c|c|c}
\hline \hline Type & $\begin{array}{c}\mathrm{E}_{\mathrm{b}} \\
\left(\mathrm{t} / \mathrm{m}^{2}\right)\end{array}$ & $\begin{array}{c}(\mathrm{t}) \\
\mathrm{cm}\end{array}$ & $\begin{array}{c}\mathrm{F}_{\mathrm{c}} \\
\left(\mathrm{t} / \mathrm{m}^{2}\right)\end{array}$ & $\begin{array}{c}\mathrm{W} \\
\left(\mathrm{KN} / \mathrm{m}^{2}\right)\end{array}$ & $\mathrm{V}$ \\
\hline \hline Tunnel liner & $2.1 \times 10^{6}$ & 40 & 4000 & 10.0 & 0.20 \\
\hline \hline
\end{tabular}

Table 3: Geotechnical soil parameters

\begin{tabular}{l|c|c|c|c|c|c}
\hline \multicolumn{1}{c|}{ Soil Parameters } & Fill & $\begin{array}{c}\text { Silty- } \\
\text { clay }\end{array}$ & $\begin{array}{c}\text { Loose } \\
\text { sand }\end{array}$ & $\begin{array}{c}\text { Medium } \\
\text { Sand }\end{array}$ & $\begin{array}{c}\text { Dense } \\
\text { sand }\end{array}$ & $\begin{array}{c}\text { Very } \\
\text { Dense } \\
\text { Sand }\end{array}$ \\
\hline \hline Drained Poisson's Ratio $\mathrm{V}_{\mathrm{s}}$ & 0.4 & 0.35 & 0.35 & 0.30 & 0.30 & 0.25 \\
\hline $\begin{array}{l}\text { Effective Angle of initial Friction }(\varphi)^{\circ} \\
(\text { drained })\end{array}$ & 25 & 26 & 27 & 32 & 38 & 43 \\
\hline Modulus Number $(\mathrm{m})$ & 300 & 350 & 300 & 500 & 800 & 1000 \\
\hline Exponent Number $(\mathrm{n})$ & 0.74 & 0.6 & 0.6 & 0.51 & 0.5 & 0.4 \\
\hline Soil density $\left(\gamma_{\mathrm{b}}\right) \mathrm{t} / \mathrm{m}^{3}$ & 1.8 & 1.9 & 1.8 & 1.85 & 1.9 & 2.0 \\
\hline Coefficient of Lateral Earth Pressure $\mathrm{K}_{0}$ & 0.58 & 0.57 & 0.56 & 0.47 & 0.38 & 0.32 \\
\hline \hline
\end{tabular}




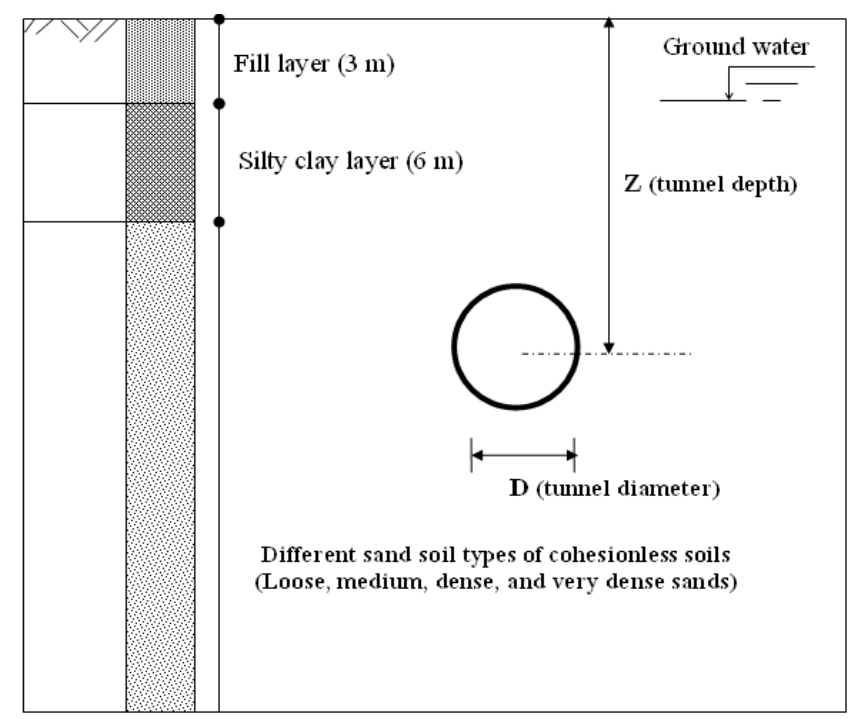

Fig. 1 Cross section along the Greater Cairo Metro tunnel Line 2 (Case study)

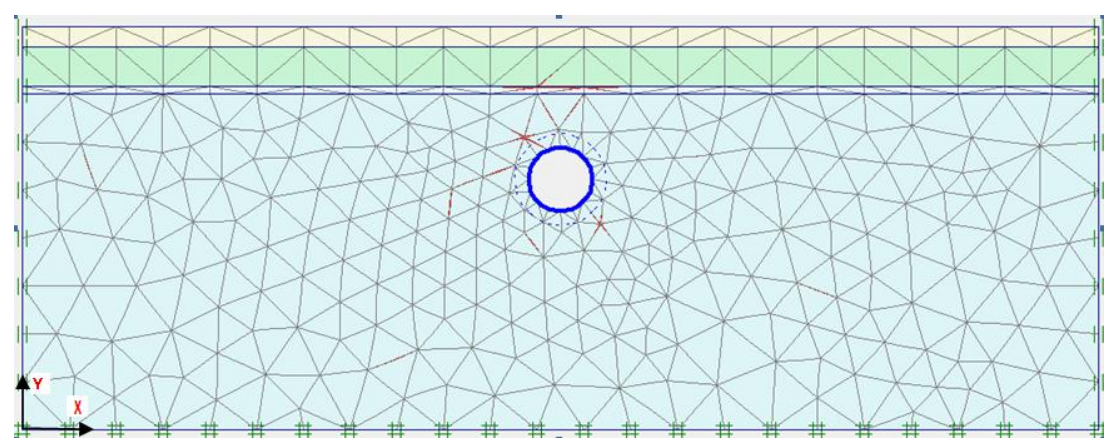

Fig. 2 2-D finite element model of the Greater Cairo Metro
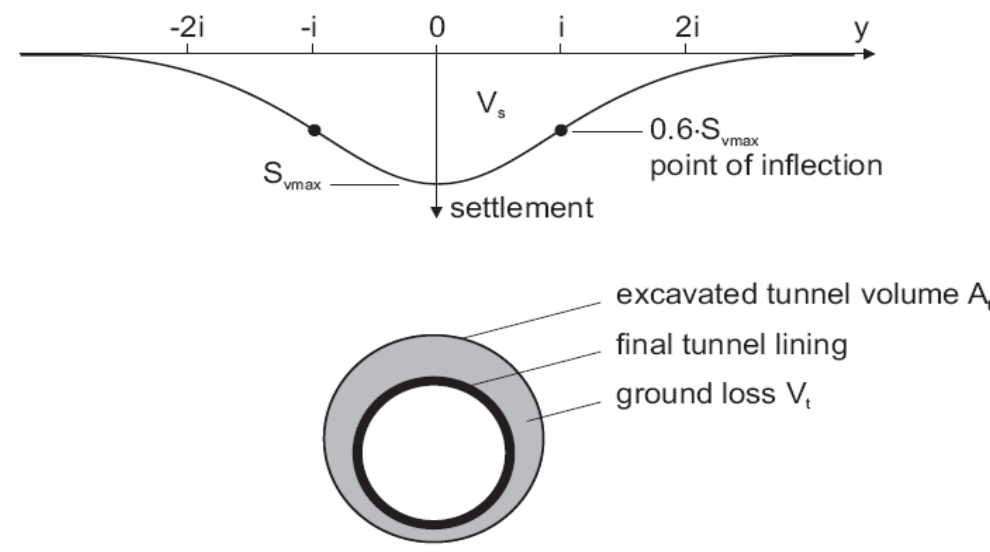

Fig. 3 Gaussian curve for transverse settlement trough and ground loss (After Peck and Schmidt, 1969) 


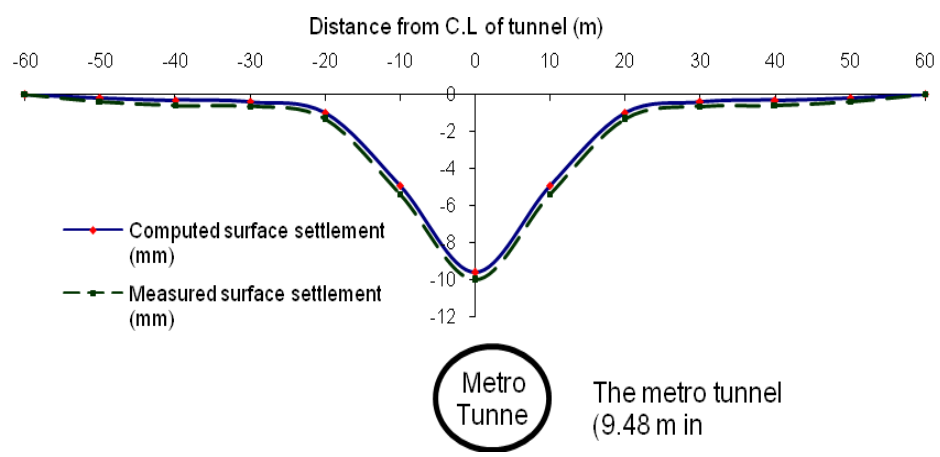

Fig.4 Comparison between measured and calculated surface settlements due to metro tunnel construction (case history)

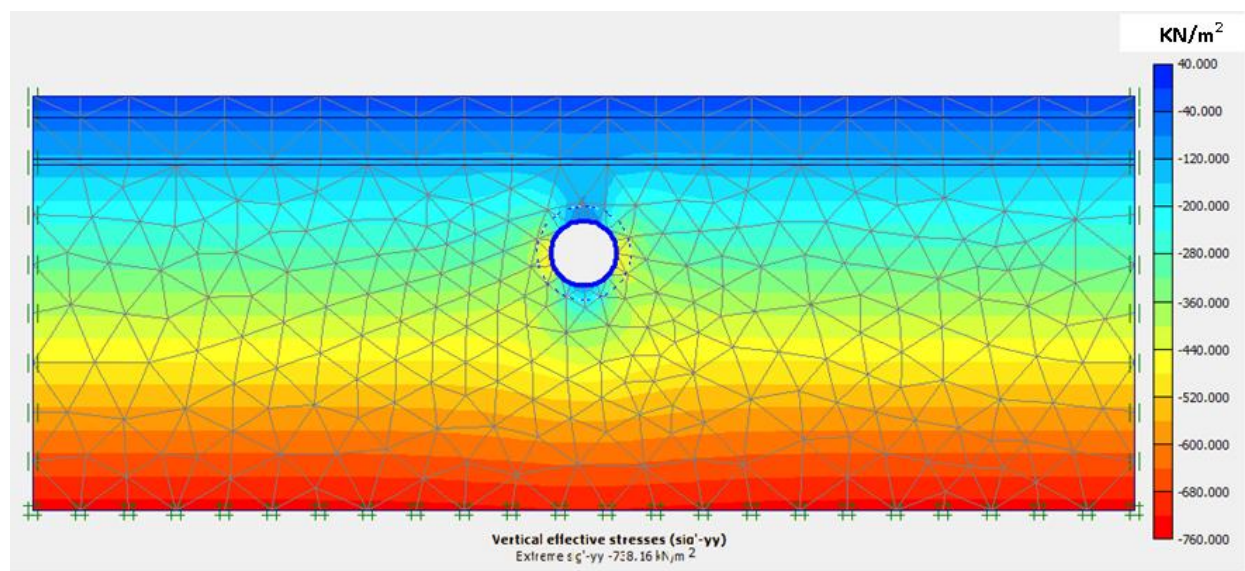

Fig. 5 Calculated vertical effective stress around the Greater Cairo metro tunnel after tunnel construction

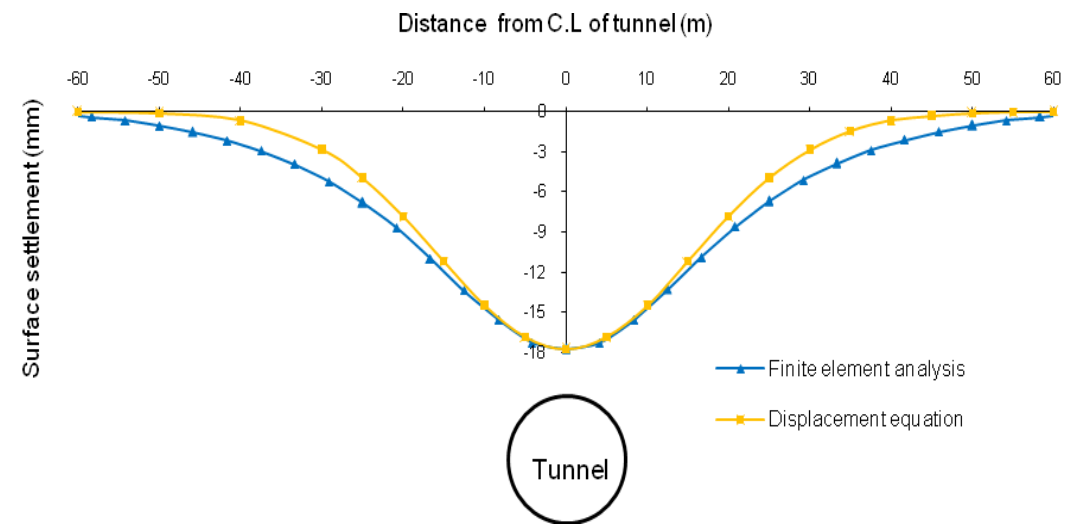

Fig. 6 Surface settlement profile obtained by both finite element analysis and surface displacement equation in loose sand (ground loss of 3\%, D=12.5 m, Z/D=2.5) 


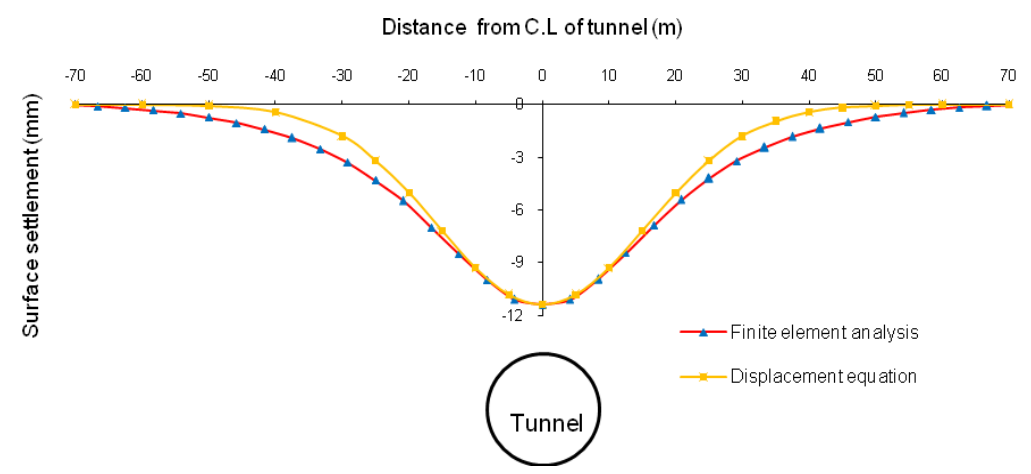

Fig. 7 Surface settlement profile obtained by finite element analysis and surface displacement equation in medium sand (ground loss of $3 \%, \mathrm{D}=12.5 \mathrm{~m}, \mathrm{Z} / \mathrm{D}=\mathbf{2 . 5}$ )

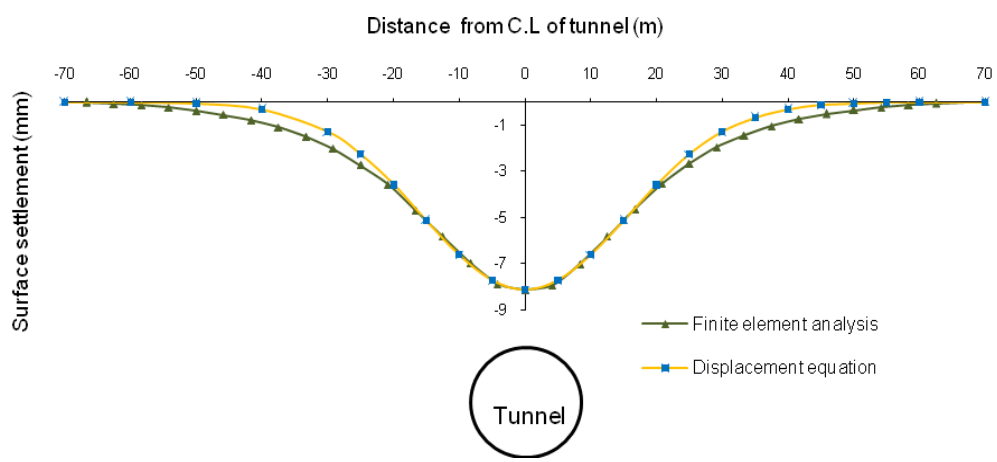

Fig. 8 Surface settlement profile obtained by both finite element analysis and surface displacement equation in dense sand (ground loss of $3 \%, D=12.5 \mathrm{~m}, \mathrm{Z} / \mathrm{D}=2.5$ )

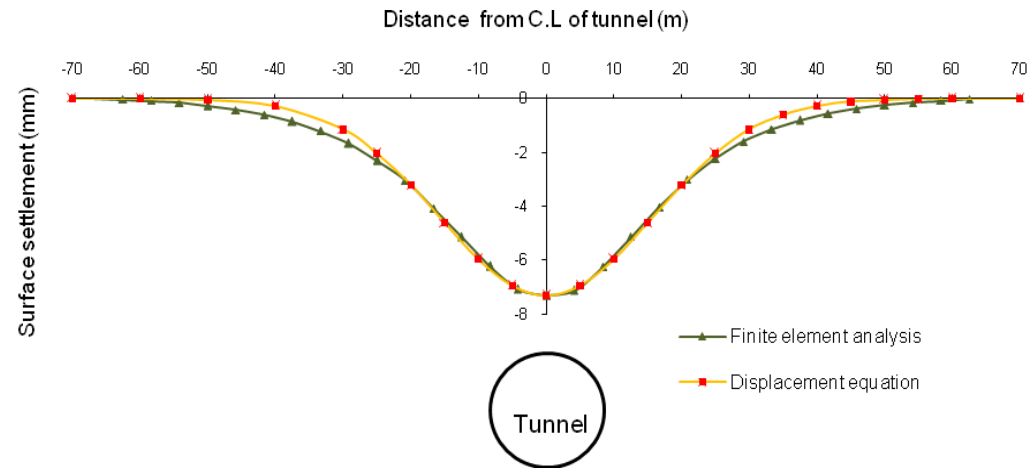

Fig. 9 Surface settlement profile obtained by both finite element analysis and surface displacement equation in very dense sand (ground loss of $3 \%, D=12.5 \mathrm{~m}, \mathrm{Z} / \mathrm{D}=\mathbf{2 . 5}$ ) 